\title{
Non-alcoholic fatty liver disease (NAFLD) in different populations: A clinical and epidemiological study - sample of São José do Rio Preto
}

\author{
Gabriel Costa de Andrade ${ }^{1 *}$, Luciana Harumi Fujise² ${ }^{2}$, Jaime Euclides de Santana Filho², Fabiane Oliveira³, \\ Rita de Cássia Martins Alves da Silva ${ }^{4}$

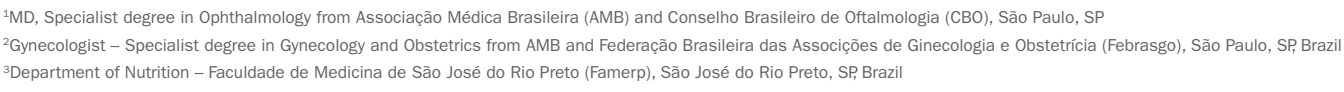

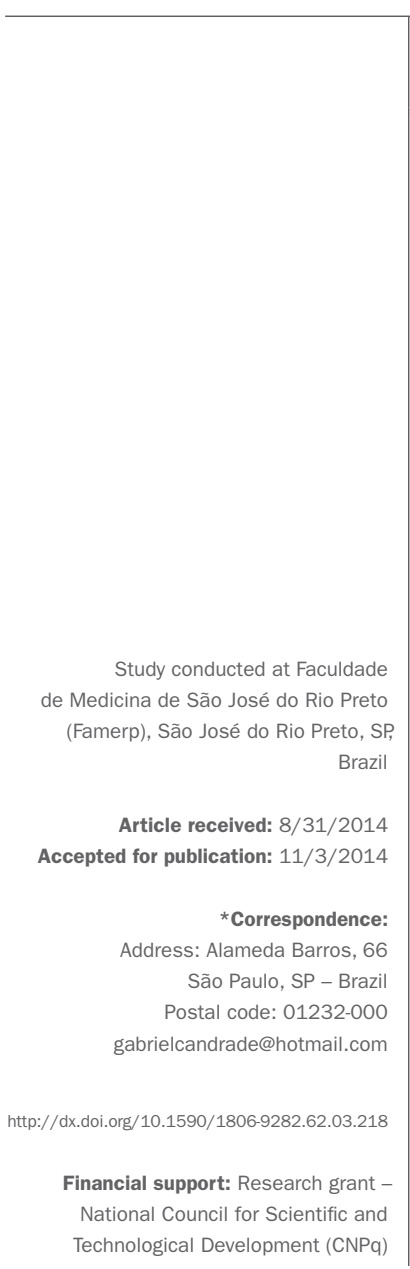

\section{INTRODUCTION}

Non-alcoholic fatty liver disease (NAFLD) represents the spectrum of a heterogeneous condition that encompasses steatosis and non-alcoholic steatohepatitis (NASH), in the absence of significant consumption of alcohol, ${ }^{27}$ which may progress into cirrhosis. Histologically, fatty liver disease is characterized predominantly by macrovesicular steatosis and NASH, and is recognized when, in association to the accumulation of fat, one or more of the following aspects are found: lobular inflammation, hepatocellular ballooning, Mallory's hyaline bodies and zone 3 perisinusoidal fibrosis. ${ }^{8,32}$

\section{SUMmARY}

Introduction: NAFLD is an heterogeneous condition that includes steatosis and non-alcoholic steatohepatitis (NASH), in the absence of significant alcohol consumption, reaching $30 \%$ of the population. The most common risk factors are: age, gender, ethnicity, diabetes mellitus (DM), obesity, predisposition, metabolic syndrome (MS), insulin resistance (IR), drugs, and polycystic ovary syndrome.

Objective: To describe the profile of patients with NAFLD seen at Hospital de Base of Rio Preto, in the state of São Paulo.

Method: Patients with NAFLD were assessed, with medical and epidemiological data collected after informed consent.

Results: Of the 62 patients evaluated, 76\% were women, $73 \%$ Caucasians, and $71 \%$ were aged between 50 and 69 years and had no symptoms. Ultrasonography results showed steatosis in $84 \%$. NASH was diagnosed in $61 \%$ of the sample. 21 patients underwent liver biopsy, of which $36 \%$ had cirrhosis, 1 had liver cancer, and 1 pure steatosis (5\% each). Risk factors were found in $70 \%$ of patients with metabolic syndrome, $87 \%$ with increased waist circumference, $63 \%$ with dyslipidemia, $61 \%(n=38)$ with high blood pressure (HBP), $28 \%$ with DM, $52 \%$ physically inactive, and 44\% with insulin resistance (IR) (HOMA>3.5). There was an association between IR and NASH $(p=0.013)$, IR and obesity $(p=0.027)$, IR and MS $(\mathrm{p}=0.006)$, and MS and steatosis on medical ultrasound (USG) $(\mathrm{p}=0.014)$. Conclusion: The most frequent risk factors were MS and its variables: increased waist circumference, dyslipidemia and HBP. This underscores the importance of metabolic control in NAFLD and confirms its role as the hepatic component of metabolic syndrome.

Keywords: fatty liver, diabetes mellitus, obesity.

Although NAFLD can remain stable and stationary for long periods of time, the condition can progress to advanced stages of cirrhosis and liver cancer. ${ }^{4,22,38,39,53,54}$ The predisposing factors to the progressive course of NAFLD remain unclear.

NAFLD prevalence is high, being reported in approximately 20 to $30 \%$ of the general population in studies based on imaging methods. ${ }^{6,56}$ For histological studies, in selected groups of patients with risk factors for this disease, the prevalence may be higher, with steatosis found in $70 \%$ of obese patients and $35 \%$ of non-obese individuals, while NASH is seen in $18.5 \%$ of obese and $3 \%$ of non-obese 
patients. ${ }^{45}$ In patients with type 2 diabetes mellitus (DM2), the frequency of fatty liver disease can reach $75 \%{ }^{17,29,48}$

Numerous individual characteristics or external conditions associated with NAFLD may play a role in the etiology, pathogenesis, natural history and progression of this disease, such as: age, gender, ethnicity, ${ }^{46,56}$ diabetes mellitus, ${ }^{2,15,38}$ obesity, ${ }^{2}$ family predisposition, ${ }^{50}$ metabolic syndrome $^{26}$ and peripheral insulin resistance. ${ }^{29}$

Some drugs such as amiodarone, tamoxifen, diltiazem, cortisone and HAART have been associated with NAFLD, and the induction of NASH is associated with prolonged therapy (longer than 6 months) and drug accumulation. ${ }^{10,20,31,37,40,50-52}$ Procedures such as total parenteral nutrition, jejunoileal or gastric bypass have been linked to fatty liver disease. An association has been described between NAFLD and rare genetic disorders such as lipoatrophy, Mauriac syndrome, ${ }^{39}$ abetalipoproteinemia, ${ }^{36}$ Andersen disease and Weber-Christian disease. ${ }^{55}$ Environmental factors such as various kinds of petrochemicals and solvents ${ }^{11-13,41}$ are related to the appearance of NAFLD. Data from the literature, in the first few studies and more, showing the variability of the risk factors for NAFLD according to gender, race and ethnicity, ${ }^{46,56}$ demonstrate the multiplicity of clinical, genetic and environmental factors associated with the heterogeneous presentation of NAFLD. There is still no consensus on the treatment of choice for this disease and there are several studies focused on the use of drugs for insulin resistance and antioxidants. ${ }^{24,34}$ In this context, studies on clinical and epidemiological aspects of the disease can add important information to the diagnostic and therapeutic management of these patients.

\section{Objective}

To describe the epidemiological and clinical profile of patients with NAFLD cared for at Hospital de Base in the city of São José do Rio Preto (SJRP).

To evaluate the risk factors, clinical and diagnostic aspects of NAFLD.

To analyze the histological aspects of NAFLD.

\section{Method}

Study design and patients selection

This clinical and epidemiological study was first submitted to the approval of the local ethics committee. Adult patients with a definitive diagnosis of NAFLD (as defined below) were evaluated. The medical records of these patients with NAFLD, obtained during its investigation and routine follow-up during the period from June 2006 to April 2007, were reviewed with the objective of completing a form created for collection of epidemiological, clin- ical and laboratory data and results from imaging and histological examinations.

\section{Diagnosis of NAFLD}

NAFLD was defined in patients as steatosis proven by biopsy or imaging examination, such as medical ultrasound (USG) and/or computed tomography (CT) and magnetic resonance imaging (MRI), associated with known risk factors, in the absence of alcohol intake greater than 20 g per day.

The diagnosis of probable NASH was defined as persistent and unexplained increase in transaminase accompanied by steatosis on USG and/or CT and/or MRI examinations of the upper abdomen, without any history of significant alcohol consumption ( $<20 \mathrm{~g}$ per day) and associated with one of the following risk factors: metabolic syndrome, overweight or obesity, diabetes mellitus, peripheral insulin resistance, drugs, environmental and other factors demonstrably associated with NAFLD.

Definitive diagnosis of NASH was based on the presence of steatohepatitis on biopsy and in the absence of significant consumption of alcohol ( $<20 \mathrm{~g}$ per day).

\section{Exclusion criteria}

We excluded patients previously submitted to stomach reduction surgery such as jejunoileal or gastric bypass, as well as liver diseases, such as hepatitis B and C, Wilson's disease, hemochromatosis and autoimmune hepatitis. Patients with incomplete or inconsistent mandatory information were not included.

\section{Study variables}

Demographic and clinical data, imaging exams and laboratory tests of all individuals, carried out at the time of the NAFLD diagnosis, in the medical records were reviewed for the purpose of completing the study protocol containing fields marked as either mandatory or optional. Being overweight was defined as a BMI $\geq 25 \mathrm{~kg} / \mathrm{m}^{2}$ and obesity as a BMI $\geq 30 \mathrm{~kg} / \mathrm{m}^{2}$. The diagnosis of diabetes mellitus was based on the criteria of the American Diabetes Association (2003). Metabolic Syndrome was defined based on the criteria of the ATP III (NCEP-ATP III, 2001) ${ }^{16}$ Clinical information included age, gender, ethnicity, clinical history, history of ingestion of medication, alcohol and illicit drugs, physical examination, and anthropometric measurements. Laboratory tests included a blood count, fasting glucose and insulin, aspartate aminotransferase (AST), alanine aminotransferase (ALT), alkaline phosphatase (ALP), gamma-glutamyl transpeptidase (GGT), albumin, lipid profile, serum iron, ferritin and fasting TIBC, 
HBs-Ag and Anti-HCV. Complete serology for viral hepatitis, HCV-RNA, autoantibodies to autoimmune hepatitis, ceruloplasmin and HFE genetic testing for hemochromatosis were studied if clinically recommended.

\section{Histological analysis}

In patients undergoing liver biopsy, the corresponding slide was submitted to review by a single pathologist. For the diagnosis and grading of NASH we used the criteria created by Matteoni, ${ }^{32}$ while for fibrosis staging followed the criteria of E. Brunt. ${ }^{8}$

\section{Statistical analysis}

Minitab software was used to evaluate the descriptive data, which was expressed as the mean and median with their variations and standard deviation, as appropriate.

Student's t-test or Mann-Whitney U tests were applied to compare continuous variables, and chi-squared test and Fisher's exact test were used for categorical variables. P value was considered as less than 0.05 .

\section{RESULTS}

After signing the informed consent form, 98 adult patients cared for at Hospital de Base, SJRP, were evaluated. Only one patient refused to participate in the study. Thirty-six patients were excluded for the following reasons: 18 patients $(50 \%)$ due to alcoholism > $20 \mathrm{~g} /$ day, 10 (28\%) patients with hepatitis B, $4(11 \%)$ patients with hepatitis C, 1 (3\%) with hemochromatosis and 8 (22\%) due the lack of data in the medical records.

\section{Characterization of the sample}

Demographic, clinical and some of the laboratory data of the 62 patients with NAFLD are represented in Table 1.47 of the 62 patients were women (76\%). Regarding race, 45 patients (73\%) were Caucasian, 15 (25\%) Black and one (2\%) Asian.

The main symptoms reported by the patients were: abdominal pain: 5 patients (8\%); dyspepsia: 2 (3\%); diarrhea: 2 (3\%); postprandial fullness: 2 (3\%); increased abdominal volume: 2 (3\%); jaundice: 1 (2\%); borborygmus: 1 (2\%); asthenia: 1 (2\%); and bitterness in the mouth: 1 (2\%). Forty-four patients (71\%) referred to themselves as being asymptomatic.

There were changes to the physical examination in 28 patients (45\%), with hepatomegaly evident in 21 patients $(34 \%)$, telangiectasia in 7 (11\%), palmar erythema in $7(11 \%)$, splenomegaly in $4(6 \%)$, jaundice in $3(5 \%)$, edema of the lower limbs in 3 (5\%) and ascites in 2 (3\%).

AST and ALT values above the reference values were found in $70 \%$ and $34 \%$ of patients, respectively. Abnormal AST/ALT ratio was found in $47 \%$ of patients. 15 patients $(24 \%)$ did not have changes to ALT and AST.

The risk factors found for NAFLD are listed in Table 2 .

There were 24 (39\%) overweight patients. 14 (23\%) of 28 obese patients were classified as grade I obesity, 10 (16\%) as grade II, and 4 (6\%) as grade III obesity.

The waist was measured in 47 of 62 patients and found compatible with metabolic syndrome in 41 cases $(87 \%)$.

\section{TABLE 1 Demographic, clinical and laboratory data of 62 patients with NAFLD.}

\begin{tabular}{llll} 
& Mean* or median & Range (min-max) & Standard deviation \\
\hline Age $($ years $)$ & $50.25^{*}$ & - & 12.61 \\
\hline Weight $(\mathrm{kg})$ & $80.97^{*}$ & - & 17.19 \\
\hline Height $(\mathrm{m})$ & $1.62^{*}$ & - & 0.08 \\
\hline BMI $\left(\mathrm{kg} / \mathrm{m}^{2}\right)$ & $30.78^{*}$ & - & 6.13 \\
\hline SBP $(\mathrm{mmHg})$ & 130 & $110-200$ & - \\
\hline DBP $(\mathrm{mmHg})$ & 80 & $60-120$ & - \\
\hline Blood sugar $(\mathrm{mg} / \mathrm{dL})$ & 94 & $73-205$ & - \\
\hline HOMA & 3.37 & $0.80-11.99$ & - \\
\hline Cholesterol $(\mathrm{mg} / \mathrm{dL})$ & $197.8^{*}$ & - & 41.77 \\
\hline HDL $(\mathrm{mg} / \mathrm{dL})$ & $46.53^{*}$ & - & 12.03 \\
\hline LDL $(\mathrm{mg} / \mathrm{dL})$ & $117.18^{*}$ & - & 36.48 \\
\hline Triglycerides $(\mathrm{mg} / \mathrm{dL})$ & 138 & $40-790$ & - \\
\hline AST $(\mathrm{U} / \mathrm{L})$ & 33 & $15-257$ & - \\
\hline ALT $(\mathrm{U} / \mathrm{L})$ & 35 & $12-296$ & - \\
\hline GGT $(\mathrm{U} / \mathrm{L})$ & 36 & $7.6-269$ & - \\
\hline
\end{tabular}

BMI: body mass index; SBP: systolic blood pressure; DBP: diastolic blood pressure; HOMA: homeostatic model assessment; HDL: high-density lipoprotein; LDL: low-density lipoprotein AST: aspartate aminotransferase; ALT: alanine aminotransferase; GGT: gamma-glutamyl transpeptidase. 


\section{TABLE 2 Risk factors for NAFLD.}

\begin{tabular}{lll} 
Risk factor & $\mathbf{n}$ & $\mathbf{\%}$ \\
\hline Dyslipidemia & $38 / 61$ & 63 \\
\hline HBP & $38 / 62$ & 61 \\
\hline Physical inactivity & $32 / 62$ & 52 \\
\hline Obesity & $28 / 62$ & 45 \\
\hline Overweight & $24 / 62$ & 39 \\
\hline Increased abdominal waist (AW) & $41 / 47$ & 87 \\
\hline DM 2 & $17 / 60$ & 28 \\
\hline
\end{tabular}

HBP: high blood pressure; DM 2: type 2 diabetes mellitus.

Abnormal high-density lipoprotein (HDL) cholesterol and triglycerides (TG) results were found in 52\% and 44\% of the 62 patients, respectively. We found changes to both HDL and TG values in 19 patients (31\%). 13 patients (21\%) showed changes to HDL alone, and 8 patients (13\%) showed alterations to the TG values.

Evaluating the blood pressure (BP) measurement of 59 patients, $51 \%$ were classified as having some degree of hypertension: 16 patients $(27 \%)$ with mild hypertension (grade 1); 13 patients (22\%) with moderate hypertension (grade 2); and 1 patient (2\%) with severe hypertension (grade 3). Among the normotensive patients, 4 (7\%) were classified as having optimum BP, $16(27 \%)$ as having normal BP and $9(15 \%)$ as borderline BP.

In the evaluation of physical activity, 30 patients claimed to be active, 3 of whom (10\%) could not inform the frequency of exercises, 23 (77\%) performed physical activity at least three days a week, $3(10 \%)$ on 2 days of the week and 1 patient (3\%) reported irregular exercise.

With regard to medication, a total of $94 \%$ of the patients reported use of at least one type of medication. The use of medication known to be associated with NAFLD was noted in $21 \%$ of patients and these drugs are listed in Table 3.

\begin{tabular}{|c|c|c|}
\hline Medication & $\mathbf{n}$ & $\%$ \\
\hline Estrogens & 7 & 11.29 \\
\hline Tamoxifen & 3 & 4.83 \\
\hline Acetylsalicylic acid (ASA) & 2 & 3.22 \\
\hline Chloroquine & 1 & 1.61 \\
\hline
\end{tabular}

Imaging and biopsy methods

Evaluating the imaging methods used in the investigation, medical ultrasound (USG) was conducted in 62 patients, and the sole imaging method used for 57 patients (92\%). USG associated with computed tomography (CT) was conducted in 2 patients (3\%), nuclear magnetic res- onance (NMR) imaging in 1 patient (2\%) and in 2 patients (3\%) it was associated with CT and MRI.

Steatosis was not evident on USG in 10 patients (16\%). Steatosis was confirmed by biopsy in 9 of these patients $(15 \%)$ and, in just one patient, there was advanced cryptogenic cirrhosis subjected to liver transplantation, with diagnosis made after removal of the cirrhotic organ. Of 52 patients who had some degree of steatosis, $8(13 \%)$ had grade 1 steatosis, 5 patients (8\%) had grade 2 steatosis, 6 patients $(10 \%)$ had grade 3 , and 33 patients $(53 \%)$ had steatosis that was not graded, with one of the patients presenting focal steatosis.

22 patients (35\%) underwent liver biopsy, with steatosis described in all of them. Non-alcoholic steatohepatitis (NASH) was found in 21 patients. Other findings in the biopsies were: hepatocellular ballooning in $16 \mathrm{pa}-$ tients $(72.72 \%)$, fibrosis in 16 patients $(72.72 \%)$, iron overload in 13 patients (59.09\%), presence of Mallory bodies in 11 patients $(50 \%)$ and the presence of a tumor in one patient (4.54\%).

Staging based on the degree of inflammation according to Matteoni ${ }^{32}$ was stage 1 in 1 patient (4.76\%), 3 in 2 patients $(9.53 \%)$ and 4 in 19 patients $(90.47 \%)$.

Staging of the degree of fibrosis according to Brunt ${ }^{8}$ was: absent in 6 patients (27.27\%), stage 1 in 4 patients (18.18\%) 2 in 3 patients (13.63\%) 3 in one patient (4.54\%) and 4 in 8 patients (36.36\%).

Other findings found in the biopsies by order of frequency were: cell retraction figures in 12 biopsies (55\%), nuclear vacuolation in $8(36 \%)$, acidophilus corpuscles in $6(27 \%)$, standard biliary portal reaction in $4(18 \%)$, ductal proliferation in $3(14 \%)$, multifocal large cell hepatocellular dysplasia in $2(9 \%)$ and liver cell rosettes associated with necrosis in 1 biopsy (5\%).

\section{Risk factors}

Metabolic syndrome

Among the 36 patients in whom metabolic syndrome could be studied, the condition was found in $70 \%$. In 26 (42\%) of the 62 patients, evaluating metabolic syndrome was not possible due to incomplete data.

3 or more criteria indicating metabolic syndrome were found in 25 patients (70\%), with 3 criteria found in 14 patients (39\%), 4 criteria in 9 patients (25\%) and 5 criteria in 2 patients $(6 \%)$. Among the 11 patients $(31 \%)$ that did not have 3 or more criteria, 5 patients (14\%) had only 2 criteria, 5 patients (14\%) had only 1 criterion, and 1 patient (3\%) had none.

Waist circumference (WC) compatible with metabolic syndrome was found in 35 (87\%) of the 41 patients in 
which this information could be collected. The average was $106.11 \mathrm{~cm}( \pm 10.48)$.

Regarding dyslipidemia, 26 (55\%) of the 47 women studied and $6(40 \%)$ of the 15 men studied were found to have abnormal HDL cholesterol values. With respect to the values for triglycerides, 27 (44\%) of the 62 patients evaluated had abnormal values for the parameters of metabolic syndrome.

With respect to mean arterial pressure (MAP) a value compatible with metabolic syndrome was evident in 21 (36\%) of the 59 patients, with the maximum values for systolic blood pressure (SBP) and diastolic blood pressure (DBP) at 200 and $120 \mathrm{mmHg}$, respectively, and minimum values for SBP and DBP at 140 and $90 \mathrm{mmHg}$, and a median of $150 \times 100 \mathrm{mmHg}$.

There was an association between metabolic syndrome and steatosis on USG $(\mathrm{p}=0.014)$. Metabolic syndrome was estimated in $69 \%$ of patients with steatosis on USG $(95 \mathrm{CI}$ $54-81 \%)$ and there is evidence that the syndrome affects the majority of these patients ( $\mathrm{p}=0.005)$.

\section{Insulin resistance}

Insulin resistance (IR) was found in 22 (44\%) of the $50 \mathrm{pa}-$ tients who had homeostatic model assessment (HOMA) index calculated. There was an association between IR and metabolic syndrome in $90 \%$ of patients with HOMA $\geq 3.5$ $(p=0.006)$. There was also evidence of an association between IR and obesity $(\mathrm{p}=0.027)$ and between IR and NASH $(\mathrm{p}=0.01)$. There was no evidence of an association between IR and waist circumference compared individually $(\mathrm{p}=0.23)$.

\section{Presence of NASH}

38 of the 62 patients studied (61\%) were classified as having NASH according to one of the criteria adopted. Of these 38 patients, 30/62 (48\%) were classified as having probable NASH and 21/62 (34\%) as having definitive NASH.

22 of the 30 patients with NASH had HOMA $\geq 3.5$ $(\mathrm{p}=0.032)$. In these patients, abnormal ALT and AST values were found in $1(5 \%)$ and $4(18 \%)$ of the patients, respectively. Both enzymes were found to be abnormal in 5 patients $(23 \%)$.

\section{Discussion}

NAFLD has gained epidemiological relevance in recent years, representing one of the leading causes of chronic liver disease in the $21^{\text {st }}$ century, and may manifest itself in different age ranges, ethnic groups and gender. The true prevalence of NAFLD is underestimated in the general population, because the disease is asymptomatic and the majority of patients start investigation due to incidental findings on USG, increased liver enzymes or check-ups. ${ }^{1}$ Recent studies indicate prevalence at around 20 to $30 \%$ in the general population. In obese patients or with diabetes mellitus it can reach up to $50 \%$ of the population. ${ }^{33}$

Most of the available studies on NAFLD include patients in hospital environments and, therefore, their characteristics may not exactly represent those expected in the general population. In Brazil, there are not many studies regarding the prevalence of NAFLD; however, among the 2,232 cases of NAFLD recorded by the Brazilian Society of Hepatology in 2004, 68\% had NASH. ${ }^{13,14}$ This case series is part of the second investigation conducted at several Brazilian centers, documenting this pathology in more detail.

In the present study, there was a predominance of NAFLD in middle-aged women, as demonstrated in previous studies. ${ }^{3,21}$ However, the actual participation of gender as a determining factor in the development of NAFLD has not yet been established, given that some studies show a higher prevalence in men or an equal distribution between the sexes. ${ }^{1,3,5,33}$

With regard to the ethnic groups studied, a higher prevalence of Caucasians (73\%) was found, followed by Black patients (25\%) and only one Asian patient (2\%). Such findings contrast with previous studies that show a higher prevalence in the Caucasian group, followed by Hispanics and Asians. ${ }^{3,5}$ It is believed that the percentage of black patients found is due to the high level of miscegenation and difficulty in defining races in the group studied and, possibly, throughout Brazil.

The vast majority of patients with NAFLD diagnosis is asymptomatic (71\%), showing that the disease can progress insidiously. Nonspecific symptoms such as abdominal pain, postprandial fullness and fatigue were found in 8,3 and $2 \%$ of patients, respectively. In the physical examination, $46 \%$ of patients had some kind of finding, with hepatomegaly being the abnormality found most frequently, as it was present in 21 patients (34\%). Peripheral signs found more often were: telangiectasia in $7 \mathrm{pa}-$ tients (11\%), palmar erythema in $7(11 \%)$ and jaundice in $3(5 \%)$ patients. Signs of liver decompensation, suggestive of more advanced degrees of disease, were also verified with the following distribution: ascites in 2 patients (3\%), splenomegaly in 4 patients (6\%) and edema of the lower limbs in 3 patients (5\%). Such findings are in agreement with previous studies, characterizing NAFLD as a disease that has few symptoms and with a nonspecific clinical presentation. ${ }^{3,18,45}$

In relation to medications used by the sample, about $21 \%$ of the patients reported using drugs known to be associated with the induction of hepatic steatosis, such as 
estrogens, tamoxifen, ASA and chloroquine. Despite these patients having risk factors for metabolic syndrome, we cannot rule out the possibility that the use of these drugs is correlated with the progression of NAFLD.

With respect to NASH, less than $2 \%$ of the causes are due to drug induction. The mechanisms of action can be divided into direct hepatoxicity and action on metabolic processes in the liver, such as mitochondrial ATP production and the metabolism of fatty acids. $20,50,51$

Tamoxifen, a drug used in patients with breast cancer to inhibit estrogen receptors in this organ alone, was found in almost $5 \%$ of the patients. Studies show that tamoxifen raises the risk of developing NAFLD/NASH only in overweight and obese women with risk factors associated with metabolic syndrome. Studies revealed that $43.2 \%$ of patients developed steatosis within 2 years of use and had their tests return to normal 1 year after the end of therapy. 7,35

Knowledge of the group of medication used by these patients was also relevant, as it showed that $40 \%$ of the patients used at least one type of anti-hypertensive and $27 \%$ used at least one anti-diabetic drug, suggesting the presence of diseases directly associated with metabolic syndrome, and also related to NAFLD.,36

Metabolic syndrome is represented by a set of risk factors, mainly related to a central deposition of fat and insulin resistance, which are found in almost $70 \%$ of patients in the sample studied. According to a previous study, the presence of 3 or more criteria for metabolic syndrome raises the risk of developing severe fibrosis, chronic liver disease and cardiovascular disease by 3.5 times. ${ }^{19,25}$ In this study, three or more criteria for metabolic syndrome were found in 25 patients (70\%).

The association between metabolic syndrome and steatosis on USG was found in $69 \%$ of the patients $(\mathrm{p}=0.014)$, corroborating the concept that NAFLD can be a hepatic component of metabolic syndrome.

Being overweight or obese was found in the vast majority of the patients (84\%). This finding is compatible among the patients with NAFLD and is consistent with the literature. ${ }^{9,30}$ Obesity, estimated using the BMI, was found in $45 \%$ of patients studied. Previous studies have estimated NAFLD at $57.5 \%$ to $74 \%$ of the obese population, showing the importance of calculating the BMI and the intense relationship between obesity and NAFLD, as well as showing that there is a direct correlation between obesity and the severity of steatosis. ${ }^{44,45}$

Waist circumference relates to the amount of visceral adipose tissue and is predictive of comorbidities such as obesity, hypertension and diabetes mellitus, relating to the pathogenesis of insulin resistance and glucose intolerance. Abnormal WC values were found in $66 \%$ of the 62 patients, and were higher than those found in the literature (42-47\%). ${ }^{45}$ However, if considering the abnormal WC values only in those cases where this datum could be measured, the percentage increases to $87 \%$. This datum may be related to the fact that the measurements were carried out on the vast majority of the obese patients, emphasizing the importance of anthropometric measurements, which is often neglected in the physical exam.

Dyslipidemia was found in 38 (62.30\%) of the $61 \mathrm{pa}-$ tients, and this prevalence is compatible with the results of other studies, which showed a frequency of 28 to $66 \% .9,30$ The most common change found was low HDL values, which was found in $32(52 \%)$ of the 62 patients. Hypertriglyceridemia was found in $27(44 \%)$ of the 61 patients from which this datum was collected. Such data differs from previous literature that indicates hypertriglyceridemia as the main component of dyslipidemia as risk factor for NAFLD. ${ }^{2,45}$ These findings can be explained by change in lifestyle, with physical activity and proper diet, associated with effective drug therapy.

High blood pressure (HBP) was found in 38 of the 62 patients studied (61\%), consistent with previous studies that describe this condition in most patients. ${ }^{5,9}$

In the literature, the frequency of insulin resistance was found in 47 to $98 \%$ of the patients, even in those without DM2. ${ }^{28,45}$ In the present study, insulin resistance based on HOMA index was present in $90 \%$ of patients with metabolic syndrome, considering HOMA $\geq 3.5$. DM2 was found in $28 \%$ of the patients, and has been associated with NAFLD between 10 and $75 \%$ in previous studies. ${ }^{45}$

Elevated AST and ALT were found in 69\% and 34\% of the patients, respectively. Aminotransferase, when abnormal, suggests the presence of inflammation and is indicated as a predictor of fibrosis in these patients, especially when there is an AST/ALT ratio $>1 . .^{34,43}$ However, normal levels do not indicate the absence of inflammation. AST/ALT ratio $>1$ was found in $47 \%$ of the 62 patients. Among patients who underwent biopsy and had fibrosis, the ratio was abnormal in $44 \%$ of them.

In previous studies, NAFLD was diagnosed on USG in 20 to $40 \%$ of the patients. ${ }^{20}$ In this sample, steatosis was present in $52(84 \%)$ of the 62 patients studied. Although the evaluation of NAFLD using USG has proven itself to be useful as an initial test in patients with suspected NAFLD, it is limited in determining the presence of inflammation and fibrosis, and it is unable to evaluate the stage of hepatic impairment. In addition, if absent on USG, this does not exclude the possibility of NAFLD. 
In the literature it is accepted that the mere presence of fat without inflammation in the liver may have a benign course, although the association of steatosis, inflammation, ballooning degeneration, Mallory bodies and fibrosis characterizes NASH, which can develop into cirrhosis and resulting complications, such as hepatocarcinoma. ${ }^{34}$ The progression from steatosis to cirrhosis and death due to its complications only occurs in less than $5 \%$ of cases; however, when steatohepatitis is present, that frequency of progression can reach up to $25 \% .{ }^{32}$ Data about the speed of the progression of this disease is scarce.

38 of the 62 patients studied (61\%) were classified as having NASH. Of these 38 patients, 30/62 (48\%) were classified as having probable NASH, that is, abnormal USG associated with increased transaminases and risk factors for metabolic syndrome, while 21/62 (34\%) had definitive NASH, that is, with a biopsy proving NASH.

The definitive diagnosis of steatosis was described in the 22 biopsies performed, with ballooning degeneration in $73 \%$ and fibrosis also in $73 \%$ of the biopsies. Grade 4 fibrosis was found in $36 \%$ of the biopsies, demonstrating the presence of cirrhosis in most patients undergoing biopsy and the importance of carrying out a biopsy in patients being investigated for NAFLD, not only for diagnosis, but also to assess the progression of the disease. In all patients that showed cirrhosis, we found clinical signs of chronic liver disease, and in patients with a severe level of fibrosis, it is suggested that there is greater risk of progression to hepatocellular carcinoma. ${ }^{47,49}$

The findings of ballooning degeneration in $73 \%$ of patients and grade 4 fibrosis in 36\% are the only data from biopsies in this study that were found in greater frequency than described in the literature, which is around 33 and $6 \%$, respectively. With respect to the presence of fibrosis of all grades, iron overload and hepatocellular carcinoma were found at a frequency similar to previous studies. Lastly, the presence of Mallory bodies in 50\% and grade 1 fibrosis in $18 \%$ represented values lower than those described previously, being found in the literature at around 80 and $27 \% .^{8,23,32}$

Other findings in the biopsy, such as standard biliary portal reaction and ductal proliferation found in 18 and $14 \%$ of the biopsies, respectively, suggest a progressive pattern of the disease. ${ }^{42}$

\section{Conclusion}

Considering the epidemic of metabolic syndrome in the modern world, the investigation of other components of this syndrome is necessary. Metabolic syndrome summarizes a large part of the systemic manifestations of insu- lin resistance. In addition to the classic components of the syndrome, new components of great clinical relevance, such as NAFLD, have been demonstrated.

Current studies indicate a growing frequency of this disease in association with metabolic syndrome risk factors, meaning that better diagnostic and prognostic investigation of NAFLD is required. As there is an important association between NAFLD and metabolic syndrome, this emphasizes a need to control their component factors and corroborates the idea that NAFLD may be a hepatic component of metabolic syndrome.

Screening for metabolic syndrome with laboratory and imaging exams should be supplemented with anthropometric measurements, which are often neglected in the physical exam.

As an insidious and progressive illness with nonspecific symptoms, NAFLD can have a malignant course, progressing to NASH, cirrhosis of the liver and hepatocellular carcinoma. Thus, liver biopsy becomes an indispensable examination for evaluating the course of the disease.

We documented NAFLD in all of its clinical forms, predominantly steatohepatitis. The most frequent risk factors were metabolic syndrome and its variables: increased waist circumference, dyslipidemia and hypertension. This underscores the importance of metabolic control in NAFLD and confirms its role as the hepatic component of metabolic syndrome.

As an insidious and progressive illness with nonspecific symptoms, NAFLD can have a malignant course, progressing to NASH, cirrhosis of the liver and hepatocellular carcinoma. Thus, liver biopsy becomes an indispensable examination for evaluating the course of the disease.

NASH was described in practically a third of the sample, while hepatocellular carcinoma was described in about $5 \%$ of patients. The findings of grade 4 fibrosis in $36 \%$ of the sample, in addition to findings of NASH and hepatocellular carcinoma, are higher than the described in the literature. This may be explained by the fact that the sample in the present study includes patients cared for at a reference center, many of whom are at an advanced stage of hepatic impairment.

\section{Resumo}

Doença hepática gordurosa não alcoólica em diferentes populações: um estudo clínico e epidemiológico - Amostra de São José do Rio Preto

Introdução: a doença hepática gordurosa não alcoólica (DHGNA) é uma condição heterogênea que inclui estea- 
tose e esteato-hepatite não alcoólica (NASH), na ausência de consumo significante de álcool, podendo atingir $30 \%$ da população. Fatores de risco mais comuns são idade, gênero, etnia, diabetes mellitus (DM), obesidade, predisposição, síndrome matabólica (SM), resistência à insulina (RI), drogas e síndrome do ovário policístico.

Objetivo: descrever o perfil de portadores de DHGNA assistidos no Hospital de Base de São José do Rio Preto, SP.

Método: foram avaliados pacientes com DHGNA e coletados dados clínico-epidemiológicos, após consentimento informado.

Resultados: dos 62 pacientes estudados, houve predomínio de mulheres (76\%), caucasoides (73\%), idade entre a quinta e sexta décadas e assintomáticos (71\%). Exame de ultrassonografia (US) mostrou esteatose em 84\%. NASH foi diagnosticada em $61 \%$ da casuística. Em 21 pacientes, biópsia hepática mostrou cirrose em $36 \%$ e câncer de fígado e esteatose pura em um paciente (5\%) cada. Dos fatores de risco, $70 \%$ dos pacientes apresentavam SM; $87 \%$, cintura abdominal alterada; $63 \%$, dislipidemia; $61 \%(\mathrm{n}=38)$, hipertensão arterial sistêmica (HAS); 28\%, DM; 52\%, sedentarismo, e em $44 \%$ encontrou-se RI (HOMA>3,5). Houve associação entre RI e NASH ( $\mathrm{p}=0,013)$, RI e obesidade $(\mathrm{p}=0,027), \mathrm{RI}$ e $\mathrm{SM}(\mathrm{p}=0,006), \mathrm{SM}$ e esteatose à US $(\mathrm{p}=0,014)$.

Conclusão: os fatores de risco mais frequentes foram SM e suas variáveis (cintura abdominal aumentada, dislipidemia e HAS), o que ressalta a importância do controle metabólico na DHGNA e corrobora o seu papel como componente hepático da SM.

Palavras-chave: fígado gorduroso, diabetes mellitus, obesidade.

\section{References}

1. Adams LA, Lymp JF, Sauver JSP, Sanderson SO, Lindor KD, Feldstein A, et al. The natural history of nonalcoholic fatty liver disease: a populationbased cohort study. Gastroenterology. 2005; 129(1):113-21.

2. Angulo P, Keach JC, Batts KP, Lindor KD. Independent predictors of liver fibrosis in patients with nonalcoholic steatohepatitis. Hepatology. 1999; 30(6):1356-62

3. Angulo P. GI epidemiology: nonalcoholic fatty liver disease. Aliment Pharmacol Ther. 2007; 25(8):883-9.

4. Bacon BR, Farahvash MJ, Janney CG, Neuschwander-Tetri BA. Nonalcoholic steatohepatitis: an expanded clinical entity. Gastroenterology. 1994; 107(4):1103-9

5. Bedogni G, Marchesini G, Tiribelli C, Bellentani S, Miglioli L, Masutti F Prevalence of and risk factors for nonalcoholic fatty liver disease: the Dionysos nutrition and liver study. Hepatology. 2005; 42(1):44-52.

6. Browning JD, Szczepaniak LS, Dobbins R, Nuremberg P, Horton JD, Cohen JC, et al. Prevalence of hepatic steatosis in an urban population in the United States: impact of ethnicity. Hepatology. 2004; 40(6):1387-95.

7. Bruno S, Maisonneuve P, Castellana P, Rotmensz N, Rossi S, Maggioni M, et al. Incidence and risk factors for non-alcoholic steatohepatitis: prospective study of 5408 women enrolled in Italian tamoxifen chemoprevention trial. BMJ. 2005; 330(7497):932.

8. Brunt EM, Janney CG, Di Bisceglie AM, Neusechwander-Tetri BA, Bacon BR. Nonalcoholic steatohepatitis: a proposal for grading and staging the histological lesions. Am J Gastroenterol. 1999; 94(9):2467-74.

9. Chalasani N. Fatty liver disease as a component of metabolic syndrome. Hepatology. 2006; 44(Suppl. 1):37A-187A.

10. Chitturi S, Farrell GC. Etiopathogenesis of nonalcoholic steatohepatitis. Semin Liver Dis. 2001; 21(1):27-41.

11. Cotrim HP, Andrade ZA, Paraná R, Portugal M, Lyra LG, Freitas LA. Nonalcoholic steatohepatitis: a toxic liver disease in industrial workers. Liver 1999; 19(4):299-304.

12. Cotrim HP, Freitas LA, Freitas C, Braga L, Paraná R, Lyra L, Carvalho F. Nonalcoholic steatohepatitis in petrochemical workers: follow up of those removed from exposure area and those who remained. Hepatology. 2002; 36:983.

13. Cotrim HP, De Freitas LA, Freitas C, Braga L, Carvalho F, Paraná R, et al Clinical and histopathological features of NASH in workers exposed to chemicals with or without associated metabolic conditions. Liver Int. 2004; 24(2):131-5.

14. Day CP. Natural history of NAFLD: remarkably benign in the absence of cirrhosis. Gastroenterology. 2005; 129(1):375-8.

15. Diehl AM, Goodman Z, Ishak KG. Alcoholic liver disease in non-alcoholics. A clinical and histological comparison with alcohol induced liver injury Gastroenterology. 1988; 95(4):1056-62.

16. Executive Summary of the Third Report of the National Cholesterol Education Program (NCEP) Expert Panel on Detection, Evaluation, and Treatment of High Blood Cholesterol in Adults (Adult Treatment Panel III). JAMA 2001; 285(19):2486-7.

17. Falchuk KR, Fiske SC, Haggitt RC, Federman M, Trey C. Pericentral hepatic fibrosis and intracellular hyaline in diabetes mellitus. Gastroenterology. 1980; 78(3):535-41.

18. Farrel GC. Drugs and steatohepatitis. Semin Liver Dis. 2002; 22(2):185-94.

19. Gholam PM, Kotler DP, Flancbaum LJ. Liver pathology in morbidly obese patients undergoing Roux-en-Y gastric bypass surgery. Obes Surg. 2002; 12(1):49-51.

20. Grieco A, Forgione A, Miele L, Vero V, Greco AV, Gasbarrini A, et al. Fatty liver and drugs. Eur Rev Med Pharmacol Sci. 2005; 9(5):261-3.

21. Hashimoto E, Yatsuji S, Kaneda H, Yoshioka Y, Taniai M, Tokushige K, et al. The characteristics and natural history of Japanese patients with nonalcoholic fatty liver disease. Hepatol Res. 2005; 33(2):72-6.

22. Ong MD, Younossi ZM. Nonalcoholic fatty liver disease (NAFLD) - two decades later: are we smarter about its natural history? Am J Gastroenterol 2003; 98(9):1915-7.

23. Kleiner DE, Brunt EE, Natta MV, Behling C, Contos MJ, Cummings OW, et al. Design and validation of a histological scoring system for nonalcoholic fatty liver disease. Hepatology. 2005; 41(6):1313-21.

24. Lima VMR. Esteatohepatite não-alcoólica (ENA) em camundongos obesos (ob/ob): avaliação do efeito citoprotetor do Yo Jyo Hen Shi Ko (YHK). São Paulo: Universidade de São Paulo-USP, 2007.

25. Lobo RA, Carmina E. The importance of diagnosing the polycystic ovary syndrome. Ann Intern Med. 2000; 132(12):989-93.

26. Lonardo A. Fatty liver and nonalcoholic steatohepatitis. Where do we stand and where are we going? Dig Dis. 1999; 17(2):80-9.

27. Ludwig J, Viaggiano TR, McGil DB, Oh BJ. Nonalcoholic steatohepatitis Mayo Clinic experience with a hitherto unnamed disease. Mayo Clin Proc. 1980; 55(7):434-8.

28. Machado M, Pinto HC. Non-alcoholic fatty liver disease and insulin resistance. Eur J Gastroenterol Hepatol. 2005; 17(8):823-6.

29. Marchesini G, Brizi M, Moreselli-Labate AM, Bianchi G, Bugianesi E, McCullough AJ, et al. Association of nonalcoholic fatty liver disease with insulin resistance. Am J Med. 1999; 107(5):450-5.

30. Marchesini G, Brizi M, Bianchi G, Tomassetti S, Bugianesi E, Lenzi M, et al. Nonalcoholic fatty liver disease: a feature of metabolic syndrome. Diabetes. 2001; 50(8):1844-50

31. Martinez E, Mocroft A, García-Viejo MA, Pérez-Cuevas JB, Blanco JL, Mallolas $\mathrm{J}$, et al. Risk of lipodystrophy in HIV-1-infected patients treated with protease inhibitors: a prospective cohort study. Lancet. 2001; 357(9256):592-8.

32. Matteoni CA, Younossi ZM., Gramlich T, Boparai N, Liu YC, McCullough AJ. Nonalcoholic fatty liver disease: a spectrum of clinical and pathological severity. Gastroenterology. 1999; 116(6):1413-9. 
33. Mattos AA. Nonalcoholic steatohepatitis. J Bras Gastroenterol. 2005; 5:160-5.

34. Miele L, Forgione A, Hernandez AP, Gabrieli ML, Vero V, Di Rocco P, Greco $\mathrm{AV}$, et al. The natural history and risk factors for progression of non-alcoholic fatty liver disease and steatohepatitis. Eur Rev Med Pharmacol Sci. 2005; 9(5):273-7.

35. Nishino M, Hayakawa K, Nakamura Y, Morimoto T, Mukaihara S. Effects of tamoxifen on hepatic fat content and the development of hepatic steatosis in patients with breast cancer: high frequency of involvement and rapid reversal after completion of tamoxifen therapy. AJR Am J Roentgenol. 2003; 180(1):129-34.

36. Partin JS, Partin JC, Schubert WK, McAdams AJ. Liver ultrastructure in abetalipoproteinemia: evolution of micronodular cirrhosis. Gastroenterology. 1974; 67(1):107-18

37. Poucell S, Ireton J, Valencia-Mayoral P, Downar E, Larrat L, Patterson J, et al. Amiodarone-associated phospholipidosis and fibrosis of the liver. Light, immunohistochemical and electron microscopic studies. Gastroenterology. 1984; 86(5 Pt 1):926-36.

38. Powell EE, Cooksley WG, Hanson R, Searle J, Halliday JW, Powell LW. The natural history of nonalcoholic steatohepatitis: a follow-up study of fortytwo patients for up to 21 years. Hepatology. 1990; 11(1):74-80.

39. Powell EE, Searle J, Mortimer R. Steatohepatitis associated with limb lipodystrophy. Gastroenterology. 1989; 97(4):1022-4.

40. Pratt DS, Knox TA, Erban J. Tamoxifen-induced steatohepatitis. Ann Intern Med. 1995; 123(3):236

41. Redlich CA, West AB, Fleming L, True LD, Cullen MR, Riely CA. Clinical and pathological characteristics of hepatotoxicity associated with occupational exposure to dimethylformamide. Gastroenterology. 1990; 99(3):748-57.

42. Richardson MM, Jonsson JR, Powell EE, Brunt EM, Neuschwander-Tetri BA, Bhathal PS, et al. Progressive fibrosis in nonalcoholic steatohepatitis: association with altered regeneration and a ductular reaction. Gastroenterology. 2007; 133(1):80-90.

43. Salgado Júnior W, Santos JS, Sankarankutty AK, Silva OC. Nonalcoholic fatty liver disease and obesity. Acta Cir Bras. 2006; 21(Suppl.1):72-8
44. Santos RR, Cotrim HP. Relevância das medidas antropométricas na avaliação de pacientes com doença hepática gordurosa não alcoólica. Rev Bras Nutr Clin. 2006; 21(3):229-32.

45. Sanyal AJ; American Gastroenterological Association. AGA technical review on nonalcoholic fatty liver disease. Gastroenterology. 2002; 123(5):1705-25.

46. Schwimmer JB, McGreal N, Deutsch R, Finegold MJ, Lavine JE. Influence of gender, race, and ethnicity on suspected fatty liver in obese adolescents. Pediatrics. 2005; 115(5):561-5.

47. Shimada M, Hashimoto E, Taniai M, Hasegawa K, Okuda H, Hayashi N, et al. Hepatocellular carcinoma in patients with non-alcoholic steatohepatitis J Hepatol. 2002; 37(1):154-60.

48. Silverman JF, O Brien KF, Long S, Leggett N, Khazanie PG, Poris WJ, Norris HT, et al. Liver Pathology in morbidly obese patients with and without diabetes. Am J Gastroenterol. 1990; 85(10):1349-55.

49. Stravitz RT, Sanyal AJ. Drug-induced steatohepatitis. Clin Liver Dis. 2003; 7(2):435-51.

50. Struben VM, Hespenheide EE, Caldwell SH. Nonalcoholic steatohepatitis and cryptogenic cirrhosis within kindreds. Am J Med. 2000; 108(1):9-13.

51. Genuth S, Alberti KG, Bennett P, Buse J, Defronzo R, Kahn R, et al. Follow-up report on the diagnosis of diabetes mellitus. Diabetes Care. 2003; 26(11):3160-7.

52. Van der Valk M, Bisschop PH, Romijn JA, Ackermans MT, Lange JM, Endert E, et al. Lipodystrophy in HIV-1 positive patients is associated with insulin resistance in multiple metabolic pathways. AIDS. 2001; 15(16):2093-100.

53. Wanless IR, Lentz JS. Fatty liver hepatitis (steatohepatitis) and obesity: an autopsy study with analysis of risk factors. Hepatology. 1990; 12(5):1106-10.

54. Wanless IR, Shiota K.The pathogenesis of nonalcoholic steatohepatitis and other fatty liver diseases: a four-step model including the role of lipid release and hepatic venular obstruction in the progression to cirrhosis. Semin Liver Dis. 2004; 24(1):99-106.

55. Wasserman JM, Thung SN, Berman R, Bodenheimer HC Jr, Sigal SH. Hepatic Weber-Christian disease. Semin Liv Dis. 2001; 21(1):115-8.

56. Weston SR, Leyden W, Murphy R, Bass NM, Bell BP, Manos MM, et al. Racial and ethnic distribution of nonalcoholic fatty liver in persons with newly diagnosed chronic liver disease. Hepatology. 2005; 41(2):372-9. 